\title{
Comprehension of Conventional Methods for Ultimate Bearing Capacity of Shallow Foundation by PLT and SPT in Southern Bhutan
}

\author{
Karma Tempa ${ }^{1,2, *}$, Nimesh Chettri ${ }^{1,2}$ \\ ${ }^{1}$ Department of Civil Engineering and Architecture, College of Science and Technology, Royal University of Bhutan, Phuentsholing \\ 21101, Bhutan \\ ${ }^{2}$ Center for Disaster Risk Reduction and Community Development Studies, Royal University of Bhutan, Phuentsholing 21101, Bhutan
}

Received December 20, 2020; Revised January 21, 2021; Accepted February 25, 2021

\section{Cite This Paper in the following Citation Styles}

(a): [1] Karma Tempa, Nimesh Chettri, "Comprehension of Conventional Methods for Ultimate Bearing Capacity of Shallow Foundation by PLT and SPT in Southern Bhutan," Civil Engineering and Architecture, Vol. 9, No. 2, pp. 375 385, 2021. DOI: 10.13189/cea.2021.090210.

(b): Karma Tempa, Nimesh Chettri (2021). Comprehension of Conventional Methods for Ultimate Bearing Capacity of Shallow Foundation by PLT and SPT in Southern Bhutan. Civil Engineering and Architecture, 9(2), 375 - 385. DOI: 10.13189/cea.2021.090210.

Copyright $\bigcirc 2021$ by authors, all rights reserved. Authors agree that this article remains permanently open access under the terms of the Creative Commons Attribution License 4.0 International License

\begin{abstract}
Shallow foundations are very distinctive in Bhutan since construction of buildings are regulated to 7-8 story and the superstructure loads are not very high compared to high-rise buildings elsewhere. However, the safety of the buildings depends primarily on the stability of the subsoil. This can be evaluated by estimating Ultimate Bearing Capacity (UBC) and it is the measure of the subsoil strength. In the current study, field test such as Plate Load Test (PLT) and Standard Penetration Test (SPT) are conducted in the study area which are most common conventional methods adopted in Bhutan given the typology of infrastructures. Detail analysis is performed for PLT and SPT data collected from southern parts of Bhutan to assess the shear stability characteristics of the subsoil. The field exploration was carried out at embedment depth of $1.5 \mathrm{~m}$ in both the tests. PLT directly provides UBC through load and settlement plot. With SPT $N$-values, UBC are estimated for square footing using empirical correlations proposed by Terzaghi 1943 and Meyerhof 1963. The results are compared to comprehend the design parameters. Both in-situ test resulted close estimation of UBC. In SPT, analysis results indicate Meyerhof's correlation more conservative suggesting safe and economical foundation design. The parametric analysis was performed to deduce and validate correlations among the parameters used. The subsoil lithology was reviewed to validate the subsoil characteristics for the southern belt of
\end{abstract}

Bhutan to which resistivity profiles of the underlying strata of the subsoil in the region have been reported similar to the investigation conducted in this study.

Keywords Plate Load Test, Standard Penetration Test, Ultimate Bearing Capacity, Shallow Foundation, Subsoil, Stability, Buildings, Bhutan

\section{Introduction}

Bhutan is located in seismically active Himalayan fringe with several moderate to high earthquake histories in the past such as 2009 Mongar earthquake (Mw 6.1) and 2011 Sikkim-Bhutan earthquake ( $\mathrm{Mw}$ 6.9). The major shear zones of the Himalayan arc are the Main Himalaya Thrust (MHT), the Main Boundary Thrust (MBT), the Main Central Thrust (MCT), the South Tibetan Detachment System (STDS), and the Indus-Tsangpo Suture Zone (ITSZ). These features span the entire Himalayan arc including the Bhutan Himalaya [1,2]. Due to high seismicity in the region and in absence of national seismic code [2,3], the height of the buildings is regulated to eight story. With recent progression in engineering trends in infrastructure development projects, Detail Project Report (DPR) is required to signify project time 
frame, planning strategy and cost estimate [4]. Geotechnical investigation becomes a part of DPR under strategic planning to study the technical feasibility and suitability of the area to be developed which is a pre-requisite for construction [4] and to predict the potentially problematic soils in the area for future precautions to the damages and reduce maintenance cost [5]. Soil settings and evaluation of engineering properties of subsoil of an area have a crucial role in construction of the building. A pocketed study to vet the subsurface profiling in localized place in Pasakha, Phuentsholing (southern Bhutan) is presented elsewhere (e.g., [6]). The current study fleshed out its domain in global state and presents results of larger stretches along the south. In any infrastructure development projects, geotechnical site investigation (GSI) plays an important role in assessing the soil properties which are important parameters for architectural and structural design of structures [7] in relation to behavior of buildings to seismic responses [8] and most importantly strength characteristics of the foundation subsoil [4]. Shear and settlement requirements are two basic criterions to be satisfied for the analysis and design of shallow foundations. The criterion on bearing capacity ensures that the foundation does not undergo shear failure under loading, while settlement requirement ensures that settlement of the structure is within the tolerance limit of the superstructure [9]. Hence, to evaluate the site characteristics, geotechnical site investigation should be carried out through preliminary physical observations at the site, laboratory test and field exploration in various pocketed zones [10]. Correlation among the soil parameters such as $N$-value, bulk unit weight, angle of internal friction and bearing capacity factors are also presented to demonstrate the influence on UBC.

PLT [11] and SPT [12] are one of the most practiced field tests [13] to establish UBC of the foundation subsoil for shallow foundation. SPT is also achievable for larger depth when boring method of sub-surface investigations are performed [4]. PLT is suitable for the soil located within a depth of less than twice the width of the bearing plate [8]. Many studies in the past have indicated empirical correlation to estimate the ultimate bearing capacity and are globally accepted as proposed by Terzaghi [14], Meyerhof [15,16], Hansen [17], Vesic [18] and Bowles [19]. Many researchers have practiced and carried out studies based on these traditional methods (e.g., $[9,20-22,41])$. The in-situ tests are regarded more accurate to evaluate the design parameters for safe and economical design of foundations which rely on UBC [13]. These conventional methods are simple and also represent closer physical models [22]. This is due to the rapid development and advancement of field-testing instruments with improved understanding of soil behavior.

Both the tests are conducted in-situ, intended for the same purpose but differs in principal and set-up. PLT is regarded direct method as UBC is acquired from observed field data. In contrast to PLT, UBC from SPT is based on penetration resistance, which are further correlated to soil parameters and dimension of the footing. The field $N$-value requires further correction for overburden pressure and dilatancy [18,23]. Additional parameters required to determine the ultimate bearing capacity through SPT includes:

Shear parameters, $c$ and $\phi$

Bulk unit weight, $\gamma$

Bearing capacity factors, $N_{c}, N_{q}$ and $N_{\gamma}$

Depth of foundation, $D_{f}$

Width of footing, $B$

From PLT, the UBC can be obtained from the load-settlement curves and safe bearing capacity of the foundation can be calculated by applying factor of safety $3.0[4,13]$. This safe bearing capacity can be used by the structural engineer to obtain the safe and economical dimensions of the footings. However, geotechnical engineer should check settlement criteria as per IS 1904-1986 [24] in both the cases which often governs the safety and stability of the underlying subsoil. Higher value of factor of safety are often recommended to obtain allowable bearing capacity [13]. It is also important for an engineer to conduct preliminary geotechnical investigation by visiting site to apprehend topography and geological conditions of the area, the physical properties of soil through visual identification and or by open pit investigation, since it may not be feasible to conduct all types of test in different soils.

We experienced practicability of PLT both in coarse and fine-grained soils. It operates well in fine grained soils, however, when conducted over coarse grained soil containing majority of gravel and sand, the anchors of the support assembly of the loading truss as shown in Figure 4(b), (c) are often uprooted when subjected to high loads. In such cases, surcharge or provisional loads should be applied at both the supports to stabilize the load increment which is also called gravity loading method [11]. Usually, the end supports of the loading truss does not get sufficient anchorage in coarse grained soils. Punching of test plate are often experienced in saturated clayey soils when high loads are applied. In such cases, larger size of the test pit is appropriate. Similarly, SPT is suitable in sandy soils with less gravel and in silty-clay soils. For rock outcrop, the penetration resistance $N$-value is usually recorded rebound as sampler does not undergo penetration. In general, the site may not be the ideal conditions, limitations and inadequacies should be realized [13].

\section{Study Area}

Tests conducted at different locations in various southern parts of Bhutan are indicated in Figure 1. Eight PLT data analyzed corresponds to three locations in 
Phuentsholing, Sarpang and Samdrup Jongkhar. Similarly, 12 SPT data were analyzed from three locations in Phuentsholing, Gedu and Sarpang and the results are conferred.

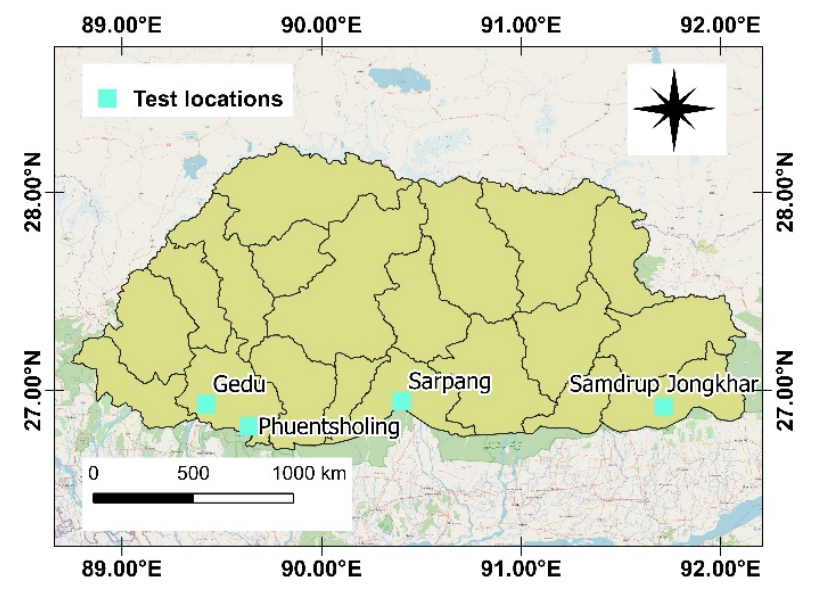

Figure 1. Study area in southern Bhutan

\section{Materials and Methods}

Field tests are considered most reliable method of investigation in geotechnical engineering practice but requires proper planning and understanding of the site conditions which decides the types of test to be conducted, number of test pits or boreholes, settings of the equipment and access to the site. Site visit and conducting preliminary investigation involving rapid visual assessment of the area largely aid the overall investigation. This includes visual identification of soils, understanding topographical features, geological scenario and observation of the probable natural hazards if any. These standard procedures $[11,12,24,25]$ in geotechnical engineering practices are carefully employed in the current study to acquire reliable in-situ data which are useful for infrastructure planning and design [4].

\subsection{Subsoil Lithology}

The regional geological setting of the Bhutan Himalaya has been meticulously described by Gansser (1983). The current study on ultimate bearing capacity of shallow foundation stretches along the Buxa group of Lesser Himalayan towards the Greater Himalayan rocks. In the south Lesser Himalayan rocks are separated from the structurally higher Greater Himalaya by the Main Central Thrust (MCT). The MCT dips to the north and divides the high-grade gneiss of the Higher Himalayan crystalline (HHC) in the hanging wall, from the greens chist metamorphic rocks of the Lesser Himalaya [26]. The bordering geology to study area comprises of Tethyan sediments of different ages (Paleozoic to Eocene) predominated by limestone, shales and sandstones [27]. Further categorizing the study area, the rock profile belongs to the Phuentsholing formation of Buxa Group of Rocks which can be broadly divided into two units: Phyllite and Quartzite. Subsurface profile depicts three major stratifications namely Stratum-I: Stiff to very stiff, light brownish grey, sandy clayey silt mixed with small size rock fragments. Stratum-II: Completely weathered, completely fractured, brownish colored, soft and weak metamorphosed Garnet-Phyllite (fully weathered mantle). Stratum-III: Completely to highly weathered, completely fractured, dark grey color, soft and weak metamorphosed Slate/Garnet- Phyllite [28].

Department of Geology and Mines (DGM) had briefly conducted subsurface investigation of regions around southern and central south Bhutan and the results are summarized herewith. Wenner's and Schlumberger arrays for the resistivity test was done which exclusively projects the 2-D profiling of the sub soil lithology. For Arong, Samdrup Jongkhar-Trashigang area, an electrode spacing of $12 \mathrm{~m}$ and the profile length of $84 \mathrm{~m}$ are maintained and the depth of section obtained using this configuration is about $20 \mathrm{~m}$. The resulting resistivity model is shown in Figure 3(a). The thin colluvium layer, observed at the surface along the profile, is underlain by a lower resistivity layer, which could be grey phyllite. The blue layer below the 48 to $60 \mathrm{~m}$ mark could be water saturated layer, clay rich (weathered phyllite) or carbonaceous phyllite [29]. Figure 3(b) shows the result of the resistivity survey for Rinchending area in Phuentsholing. The resistivity survey maintains spacing of electrodes as $5 \mathrm{~m}$. The profile clearly indicates the geological deposition of alluvium and colluvium typically of carbonaceous phyllite with coarse granular soils. Pockets of Quartzite deposition are present along the profile $(40-160 \mathrm{~m})$. A layer of phyllite was also detected beneath the quartzite deposit till the depth of 30 to $40 \mathrm{~m}$ approximately [30].
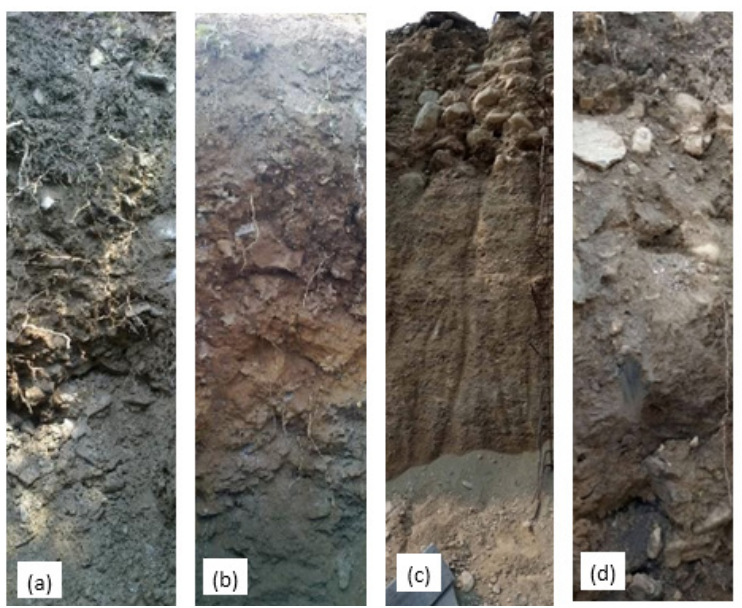

Figure 2. Random trial pit profiles (approximately 3.0m): (a) Sarpang, (b) Toribari (Pasakha), (c) Phuentsholing town, (d) Samdrup Jongkhar 

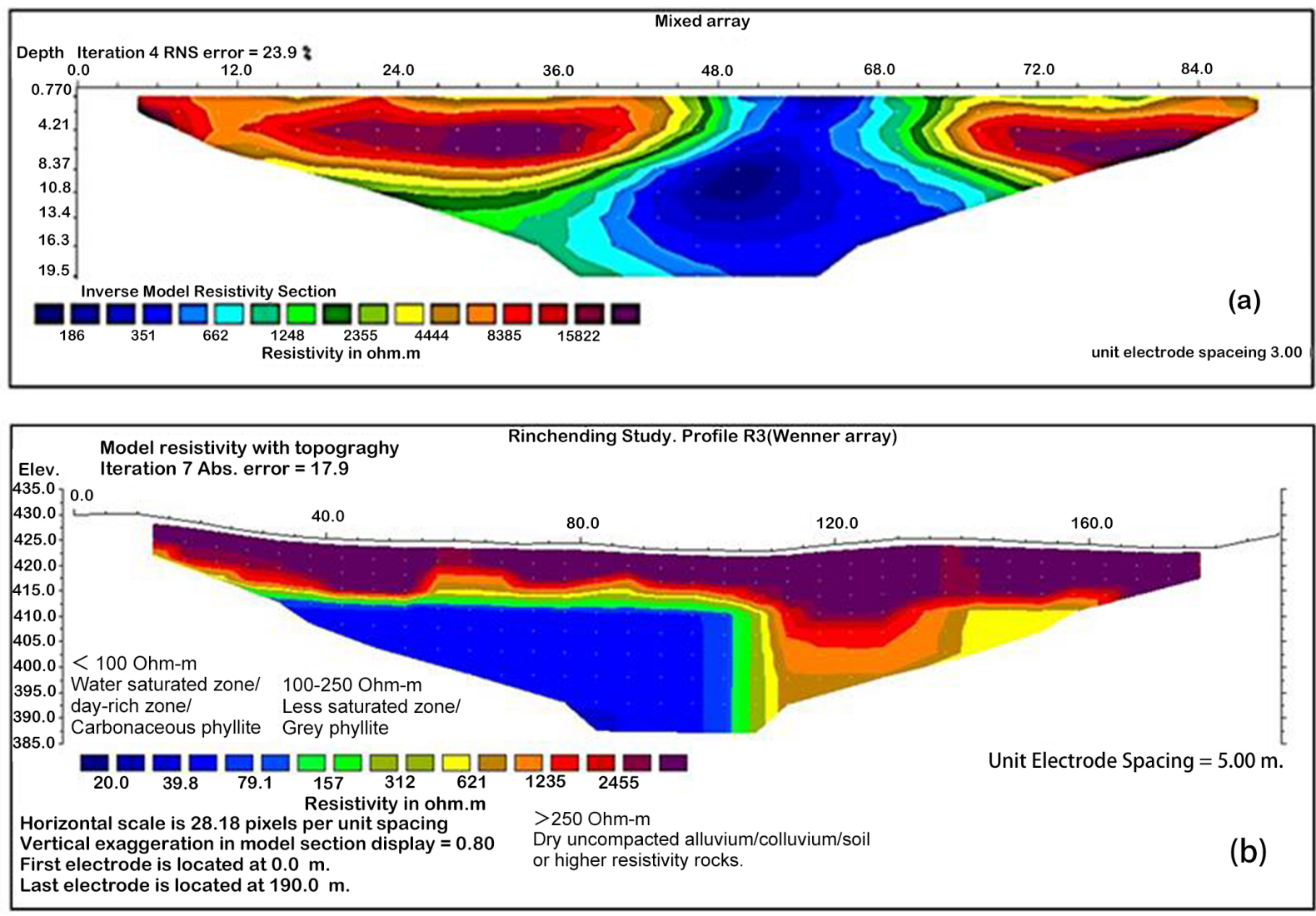

Figure 3. Resistivity profile of southern Bhutan, (a) Arong, Samdrup Jongkhar-Trashigang highway [29], (b) Phuentsholing area [30]

Upon investigation of sites in various study regions through open pit investigation, the shallow profiling (Figure 2) closely resembles the resistivity results. The trial pits of depth approximately $3.0 \mathrm{~m}$ has been excavated and various layers of soil lithology has been studied visually and further laboratory test was conducted by sieve analysis to obtain the grain size distribution (Table 1) as per IS: 2720 (Part 4)-1985 [31]. Essentially it comprises of disturbed gravels of phyllite and quartzite with little fines of alluvium deposits.

\subsection{Plate Load Test}

PLT consists (Figure 4,5) of loading truss with two support anchorage assembly, test plate, settlement dial gauges, magnetic base stand, hydraulic jack, load dial gauges, iron pegs and datum bars. Based on the soil type, the size of the test plate is decided and dimension of the overall test pit can be adopted suitably (Table 2). The loads on the steel truss assembly is applied through hydraulic system facilitated with jack. The reaction forces acts download through the loading column and the subsoil settlements are recorded using at least three dial gauges which are placed diagonally at the corner of the test plate with the help of magnetic stand. Settlement was observed for each increment of load after an interval of 1, 4, 10, 20,
40, and 6 minutes and thereafter at hourly intervals [11]. The loading is applied in increments of $250 \mathrm{~kg}$ in case of loose to medium compact sandy soils, $500 \mathrm{~kg}$ in case dense sandy soils and $1000 \mathrm{~kg}$ in very dense soils, or in increments of $1 / 5$ of design load up to a maximum of twice the design load or when the plate starts sinking at rapid rate, whichever earlier. The test terminates when the subsoil fails or the rejection of load is observed.
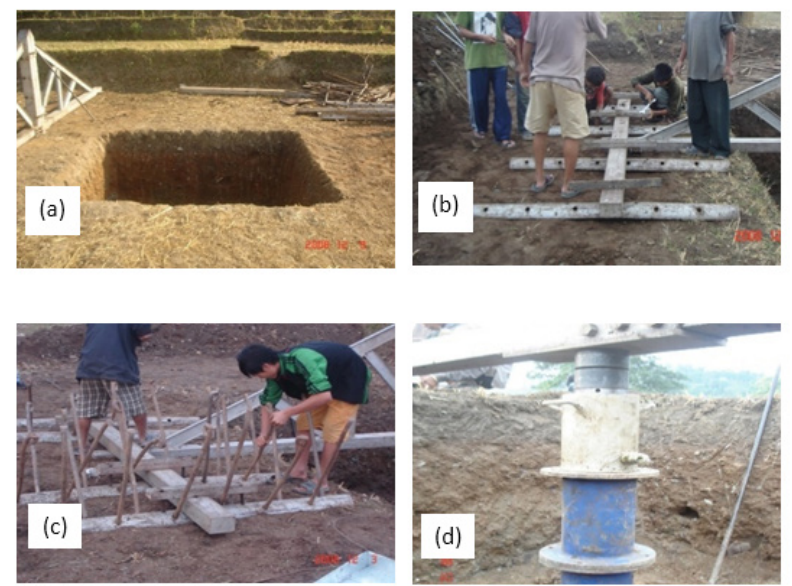

Figure 4. Plate load test setup procedure, (a) Preparation of test pit, (b) Laying of support column, (c) Anchor details, (d) Hydraulic jack and loading column 


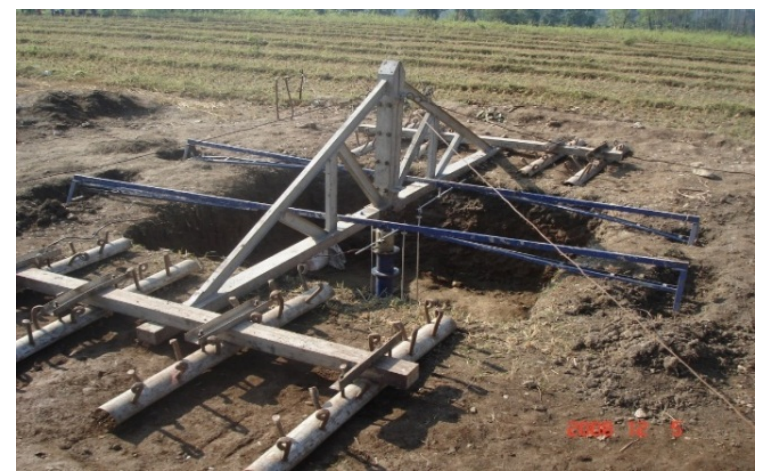

Figure 5. Overall set-up of the Plate Load Test (PLT)

Table 2. Size of the test plate based on the soil type

\begin{tabular}{ccc}
\hline Type of soils & $\begin{array}{c}\text { Test plate } \\
(\mathrm{m})\end{array}$ & $\begin{array}{c}\text { Test pit } \\
(\mathrm{m})\end{array}$ \\
\hline Gravely sandy soils with less fines & $0.3 \times 0.3$ & $1.5 \times 1.5$ \\
Sandy soils with gravel and fines & $0.45 \times 0.45$ & $2.25 \times 2.25$ \\
Silty sand or sandy soils with clay & $0.6 \times 0.6$ & $3.0 \times 3.0$ \\
\hline
\end{tabular}

\subsection{Standard Penetration Test}

SPT was conducted confirming to IS: 2131-1981 $[12,23,33]$. The test provides penetration resistance $N$-value which is also the bow counts of last $30 \mathrm{~cm}$ penetration of split spoon sampler driven by hammer weight of $65.0 \mathrm{~kg}$ from $75 \mathrm{~cm}$ height through guide pipe assembly. The split spoon sampler is connected by the extension rod called A-drill rod and are useful for deeper exploration. The split spoon sampler is marked with $45 \mathrm{~cm}$ penetration depth and driven into the soil. The number of blows required to drive each $15 \mathrm{~cm}$ mark is noted. However, blow count of first $15 \mathrm{~cm}$ is considered as seating value or seating load. The number of blows required to penetrate last $30 \mathrm{~cm}$ is called as the $N$-value $[23,33]$. In order to further utilize the $N$-value, it was corrected for overburden pressure and checked for dilatancy correction to get $N$-corrected ' $N$ cor' and corresponding $\phi$-value were correlated. SPT equipment consist of tripods stand, hammer weight, pulleys and split spoon sampler as shown in Figure 6. In SPT test, for shallow depth $(<2.0 \mathrm{~m})$ of foundation, smaller the size of the pit size is required. For larger depth of the foundation $(2-4.0 \mathrm{~m})$, bigger the size of the test pit is recommended to comfortably conduct the test.

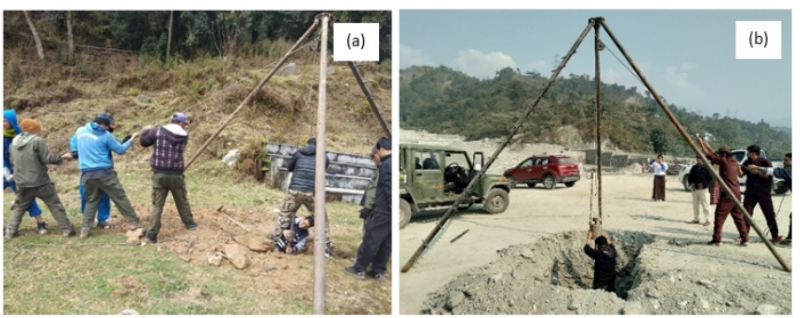

Figure 6. (a), (b) Standard penetration test at the sites

\section{Results and Discussions}

\subsection{Sieve Analysis}

Sieve analysis conducted for samples collected from open pit indicate coarse grained soils containing larger portion of sand between $45-65 \%$ followed by gravel of $22-37 \%$ and less than $10 \%$ silt and clay content in the study region (Table 1). The soil is classified as non-plastic poorly graded sand (SN-NP) as per IS: 1498-1970 [25].

Table 1. Grain size distribution in study regions

\begin{tabular}{cccccc}
\hline Locations & $\begin{array}{c}\text { Boulders } \\
>300 \mathrm{~mm} \\
(\%)\end{array}$ & $\begin{array}{c}\text { Cobles } \\
\begin{array}{c}300-80 \mathrm{~mm} \\
(\%)\end{array}\end{array}$ & $\begin{array}{c}\text { Gravel } \\
80-4.75 \mathrm{~mm} \\
(\%)\end{array}$ & $\begin{array}{c}\text { Sand } \\
4.75-0.075 \mathrm{~mm} \\
(\%)\end{array}$ & $\begin{array}{c}\text { Silt and Clay } \\
<0.075 \mathrm{~mm} \\
(\%)\end{array}$ \\
\hline Sarpang & 0 & 5.62 & 36.46 & 54.56 & 3.36 \\
Phuentsholing town & 2.14 & 6.14 & 38.75 & 48.56 & 6.41 \\
Toribari (Pasakha) & 4.52 & 5.24 & 22.12 & 54.32 & 5.80 \\
Samdrup Jongkhar & 3.24 & 6.56 & 26.54 & 54.62 & 9.04 \\
\hline
\end{tabular}




\subsection{UBC from PLT}

In conjunction with the various PLT test conducted in Bhutan, the details presented in Table 1 are suggested for the choice of size of test plate and corresponding size of the test pit.

The setup of the PLT is carried out as shown in Figure 4,5 . According to the results presented in this paper, the soils in terms of its bearing capacity are soft to medium type of soil with moderately dense soils which confirms to IS 1893: 2002 [32]. The ultimate bearing capacity ranges between 275 to $785 \mathrm{kN} / \mathrm{m}^{2}$ approximately as shown in Figure 7, 8 from eight PLT test data. The higher value indicates dense sands like in the case at Toribari-3.

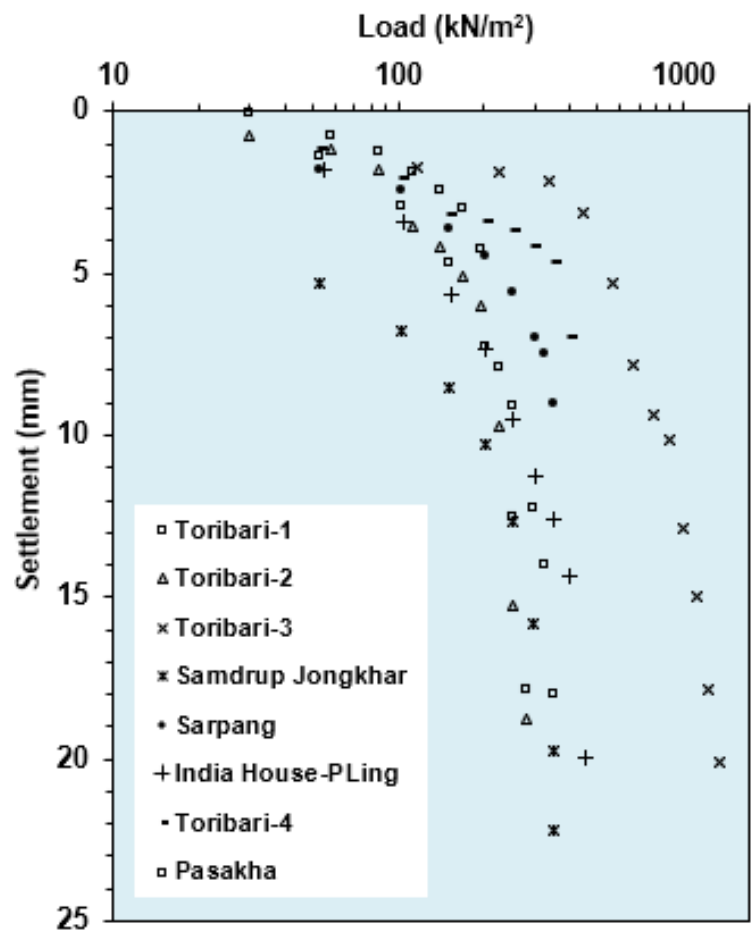

Figure 7. Load-settlement curve for ultimate bearing capacity

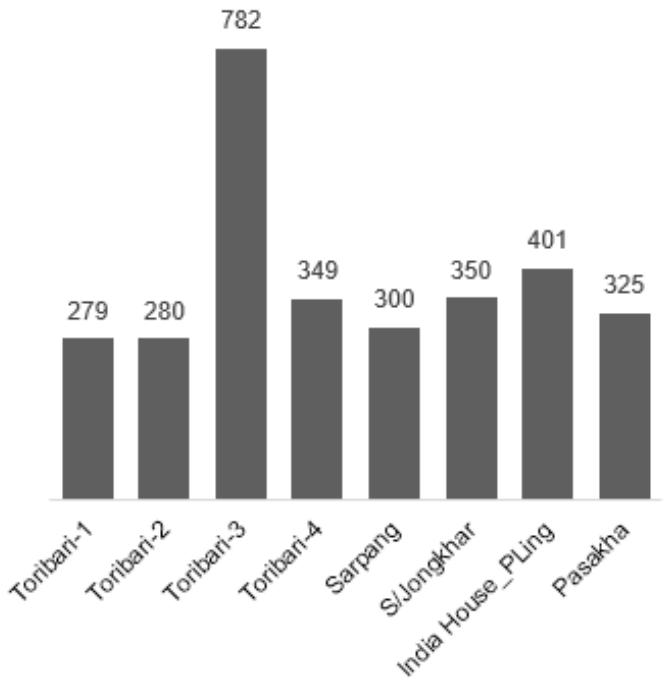

Figure 8. Ultimate bearing capacity for respective test sites from PLT

\subsection{UBC from SPT}

Field $N$-value is primary source of data to estimate the ultimate bearing capacity, however, many other dependent soil parameters are required. Estimation of ultimate bearing capacity is challenging with uncertainty with many soil parameters [34]. Field density of the in-situ soil is one of the main soil properties that largely influence the ultimate bearing capacity as it reveals physical characteristics at the particular site with the actual moisture content. It is defined as the weight of unit volume of soil present at a site and is also called bulk unit weight $(\gamma)$. The penetration resistance $N$-value and field density show significant relationship as both are in-situ values similar to relative density [35]. In the current study, field density was obtained by conducting Core-Cutter method as per IS: 2720 (Part-29)-1975 [23,36,37]. The correlation between $N$-value and field density is unique and most relevant in geotechnical engineering. For $\mathrm{N}$-value between 7-16, the field density ranges from 12 to $17 \mathrm{kN} / \mathrm{m}^{3}$ approximately. As per the regression analysis, the empirical relation between these two field parameters produced correlation coefficient, $\mathrm{R}^{2}=0.7530$ (Figure 9) and the equation can be represented as in Equation 1. This equation is considered applicable only to the study region with similar soil characteristics.

$$
\gamma_{t}=0.41 N+10.32
$$

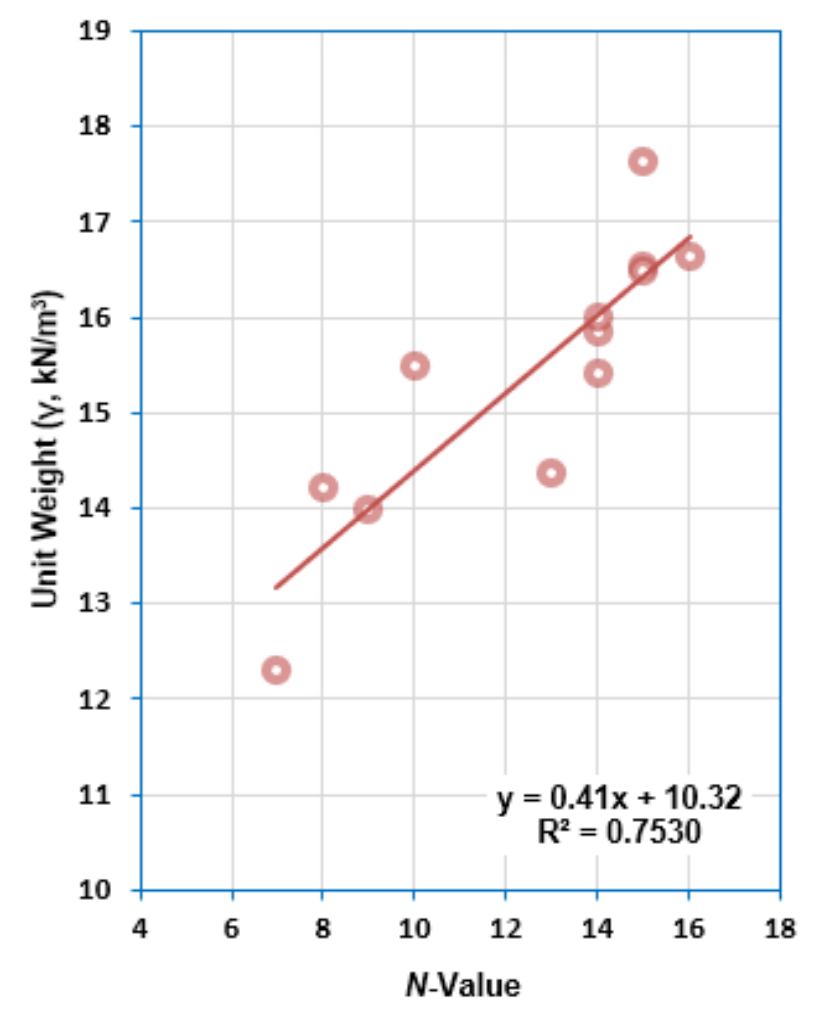

Figure 9. Correlation between unit weight and $N$-values of the study locations

The $N$-value in cohesionless soils is influenced by the depth at which the test is conducted. Because of increased 
overburden pressure due to greater confinement of the subsoil strata, $N$-values at increasing depths indicate different relative densities than actual one. Hence, overburden correction was applied by Equation 2 proposed by Peck et al. 1974 [18,38].

$$
C_{N}=0.77 \log \frac{2000}{\sigma^{\prime}}
$$

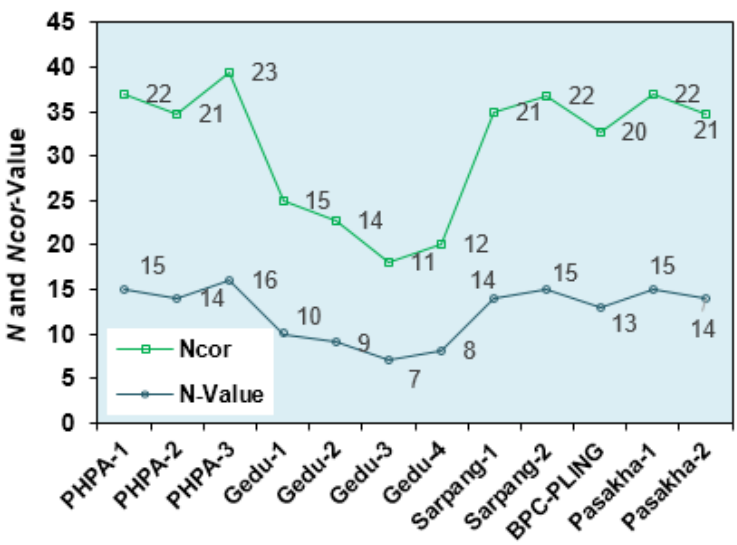

Figure 10. Penetration location in different test locations

In all the test locations, there was no water table indication at the depth of exploration and dilatancy corrections were not necessary. The variation of corrected $\mathrm{N}$-values to the field values are shown in Figure 10.

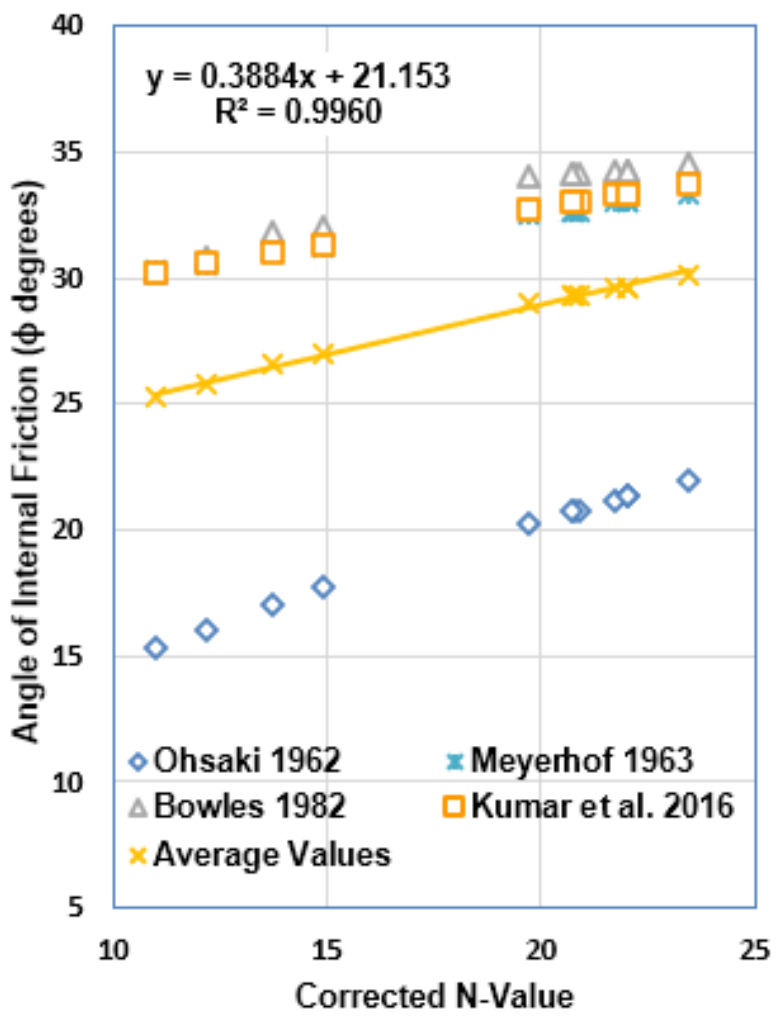

Figure 11. Correlation plot between $\phi$ and $N$-values
Based on the corrected $N$-values, the angle of internal friction $(\phi)$ was correlated as proposed by Meyerhof 1963 [16,18,33,35,39], Ohsaki 1962 [40], Bowles 1996 [19] and Kumar et al. 2016 [41] in the current study. An average value with correlation coefficient $\mathrm{R}^{2}=0.9960$ (Figure 11) was used for the current study to obtain the bearing capacity factors for all the sites. Angle of internal friction are the most important soil parameter which defines the soil type for which ultimate bearing capacity depend on. It ranges from $25-30^{\circ}$ for corrected $N$-value between 11-23. In present study, ultimate bearing capacity was estimated for square footing at the foundation depth of $1.5 \mathrm{~m}$ below the ground surface using $N$-values by Terzaghi and Meyerhof formula and parametric studies are conducted to draw the inferences pertaining to foundation design.

Bearing capacity factors are related to angle of internal angle of friction which is used in empirical equation to derive ultimate bearing capacity. Different bearing capacity factors are proposed by many researchers $[14,15,17,33]$ and these factors have similar acceptance. In the current study, bearing capacity factors are correlated with the Terzaghi 1943 and Meyerhof 1963 proposals as presented in Figure 12, 13. The exponential relationship between the two mentioned parameters is well observed and established in the current study since bearing capacity factors show exponential function of $\phi$ [13].

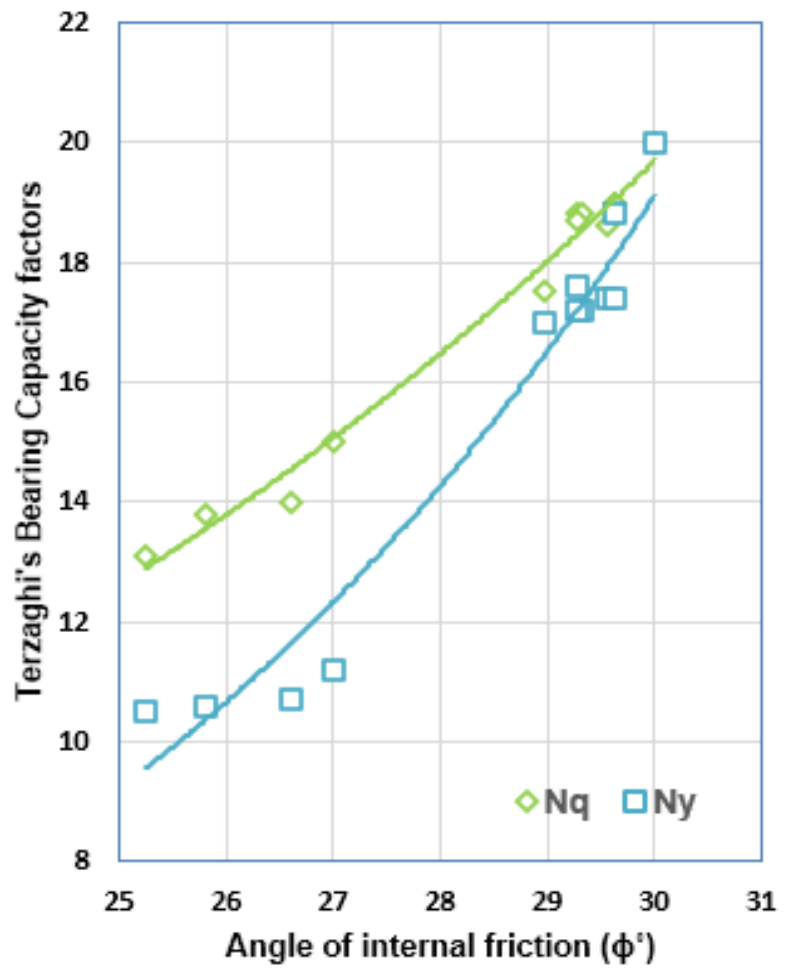

Figure 12. Terzaghi's bearing capacity factors Vs. angle of internal friction 


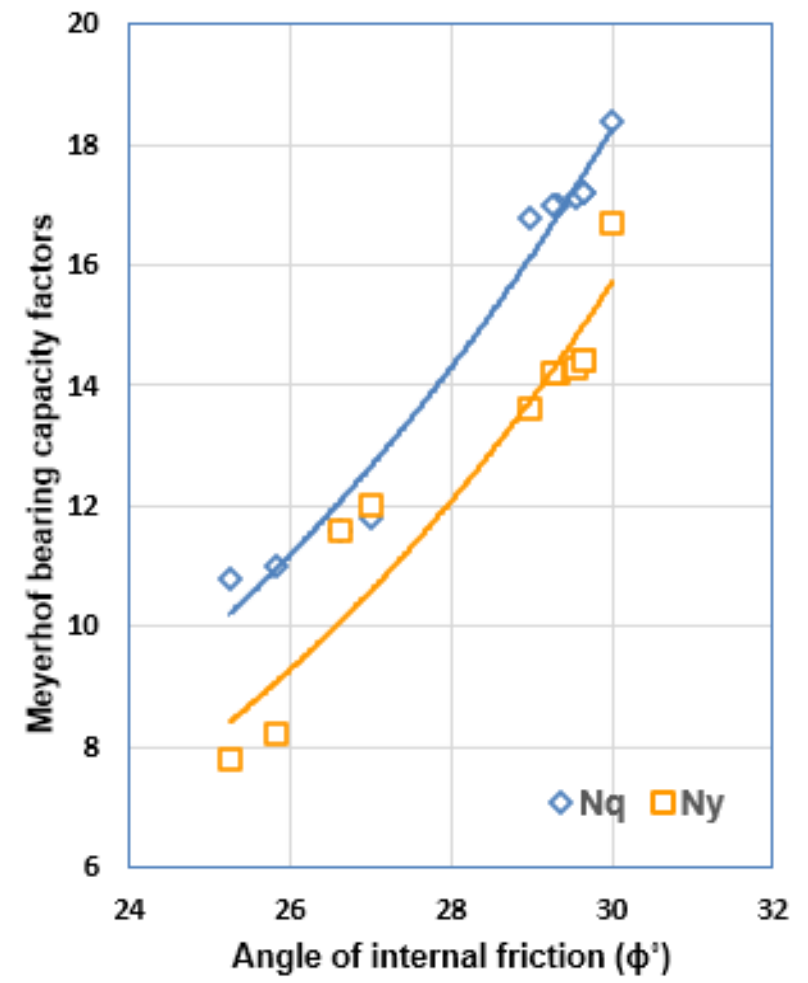

Figure 13. Meyerhof's bearing capacity factors Vs. angle of internal friction

Terzaghi 1943 [14] initially proposed ultimate bearing capacity for strip footing but later revised to other types of footings considering various types of shear failure modes. Terzaghi 1943 ultimate bearing capacity Equation $[14,18,33,39,42,43]$ is given by Equation 3 .

For strip footing:

$$
q_{u l t}=c N_{c}+q N_{q}+0.5 \gamma B N_{\gamma}
$$

For square footing:

$$
q_{u l t}=1.2 c N_{c}+\bar{q} N_{q}+0.4 \gamma B N_{\gamma}
$$

where,

$q_{u l t}$ ultimate bearing capacity

$c$ cohesion parameter

$\bar{q}$ overburden pressure equal to $\gamma D_{f}$

$N_{c}, N q, N_{\gamma}$ non-dimensional bearing capacity factors an exponential of $\phi$

$\gamma$ bulk unit weight of soil

$D_{f}$ embedment depth of foundation

$B$ width of the footing

Further, Meyerhof [14], Hansen [17] and Vesic $[18,33,39,42-44]$ applied modification factors (Table 3) to the original Terzaghi bearing capacity equation, which was conservative [13] and is represented commonly by the following general Equation 5:

$$
q_{u l t}=c N_{c} s_{c} i_{c} d_{c}+\bar{q} N_{q} s_{q} i_{q} d_{q}+0.5 \gamma B N_{\gamma} s_{\gamma} i_{\gamma} d_{\gamma}
$$

where,
$s_{c}, s_{q}, s_{\gamma}$
non dimensional shape factors
$i_{c}, i_{q}, i_{\gamma}$ non-dimensional inclination factors
$d_{c}, d_{q}, d_{\gamma}$
non-dimension depth factors

Table 3. Meyerhof's correction factors applied in current study for cohesionless soils

\begin{tabular}{ccc}
\hline $\begin{array}{c}\text { Correction } \\
\text { factors }\end{array}$ & Expression & In current study \\
\hline$s_{c}$ & - & Not applicable \\
& $1+0.1 \frac{B}{L} \tan ^{2}\left[45^{\circ}+\frac{\phi}{2}\right]$ & $\begin{array}{c}\text { For square footing, } B / L \\
=1.0\end{array}$ \\
$s_{q}, s_{\gamma}$ & for $\phi^{*}>10^{\circ}$ & Not applicable \\
& - & Not applicable \\
$i_{c}, i_{q}, i_{\gamma}$ & - & $\begin{array}{c}\text { Depth of embedment }, D \\
=1.5 \mathrm{~m}\end{array}$ \\
$d_{c}$ & & $\begin{array}{l}\text { Width of footing, } B= \\
\end{array}$ \\
$d_{q}, d_{\gamma}$ & $1+0.1 \frac{D}{\tan }\left[45^{\circ}+\frac{\phi}{2}\right]$ & $1.0,1.5,2.0,2.5,3.0$, \\
& for $\phi^{*}>10^{\circ}$ & $3.5,4.0,5.0$ and $6.0 \mathrm{~m}$ \\
\hline
\end{tabular}

* $\phi$-values corresponds to different site locations

The ultimate bearing capacity obtained from Meyerhof 1963 formula indicate higher results compared to Terzaghi 1943 estimation and it is obvious that the former results are more conservative than the later due to provision of shape and embedment depth correction factors, although shape factor for square footing (Equation 4) in the current study had been incorporated as proposed by Terzaghi 1943 .

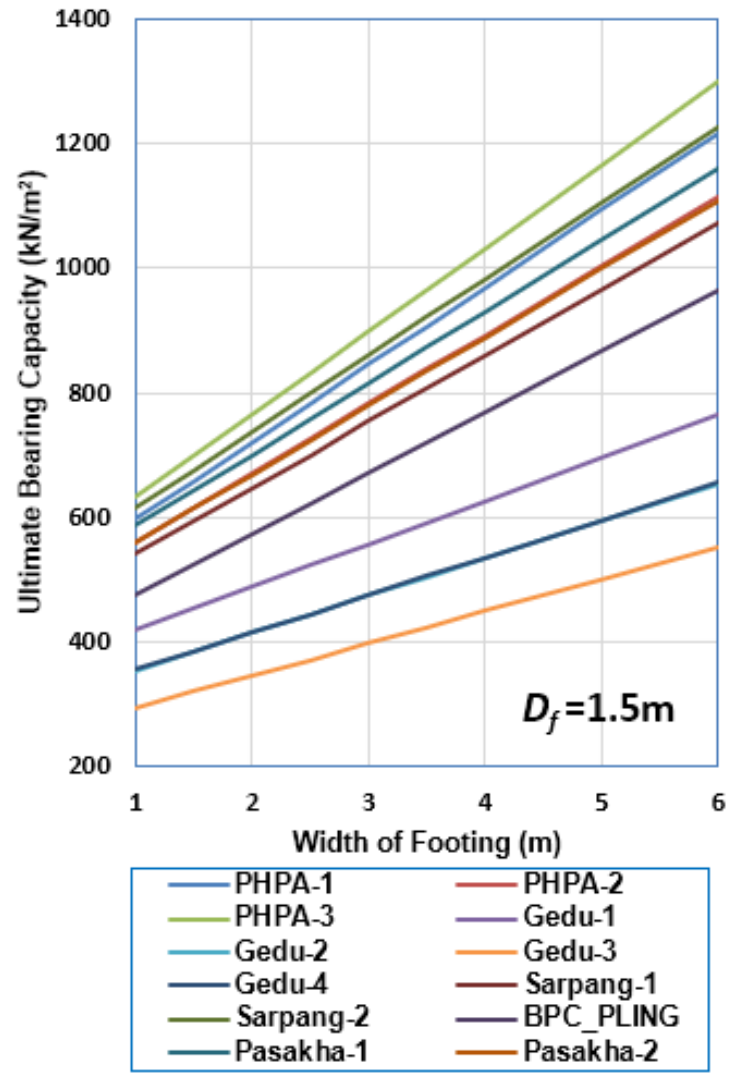

Figure 14. Terzaghi's (1943) ultimate bearing capacity for corresponding width of the foundation for all study locations 


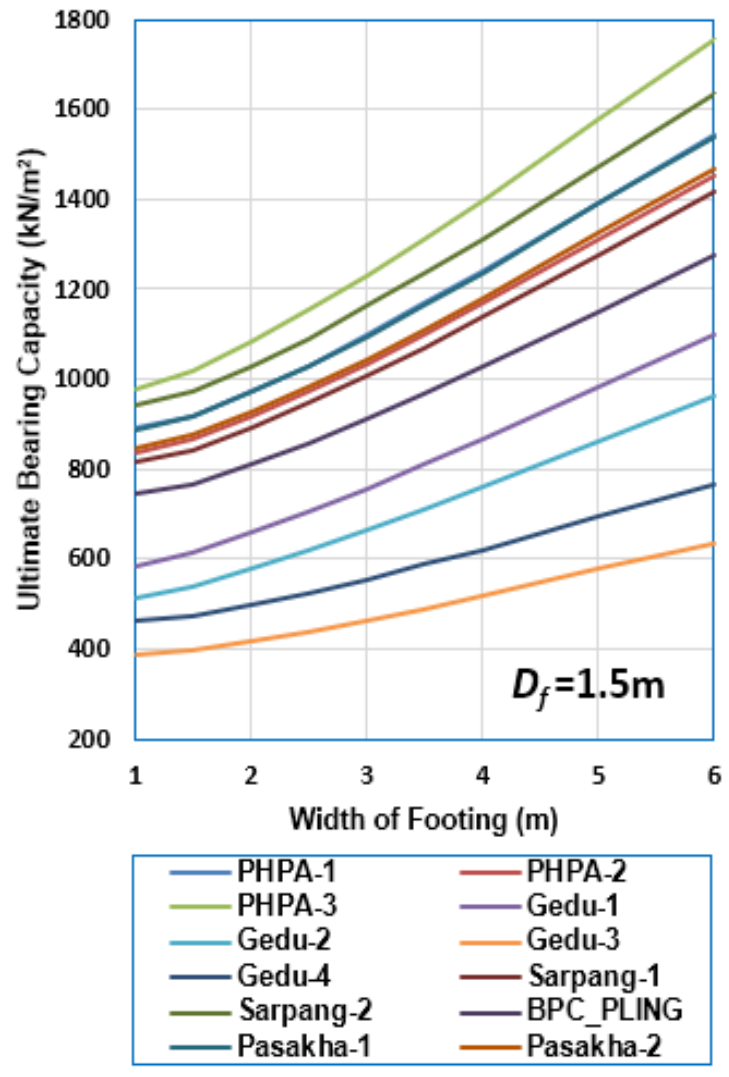

Figure 15. Meyerhof's (1963) ultimate bearing capacity for corresponding width of the foundation for all study locations

The ultimate bearing capacity is minimum as 294 $\mathrm{kN} / \mathrm{m}^{2}$ for lower width of footing and maximum up to $1300 \mathrm{kN} / \mathrm{m}^{3}$ approximately for higher width of footing with Terzaghi's correlation. On the other hand, Meyerhof's approximation had indicated minimum of 389 $\mathrm{kN} / \mathrm{m}^{2}$ at lower width of footing and $1754 \mathrm{kN} / \mathrm{m}^{2}$ for higher footing width. The progression trend in both the case are similar and linear having least ultimate bearing capacity in Gedu-3 and highest in PHPA-3 for the respective corresponding foundation width as presented in Figure 14, 15. All the test site at Gedu exhibit characteristics of local shear failure of the foundation subsoil $\left(\phi<28^{\circ}\right)$ and the translational or mix mode of shear failure at all other sites $\left(28^{\circ}<\phi<38^{\circ}\right)$.

Since, unit weight obtained through field test show significant relationship with the $N$-value, the variation of ultimate bearing capacity with the field density with the unit width of the footing is linear in nature as per the findings. The analysis results depict correlation coefficient $\mathrm{R}^{2}=0.8199$ and similarly, the correlation between angle of internal friction and the ultimate bearing capacity produced $\mathrm{R}^{2}=0.9632$ suggesting conceivable approximation of ultimate bearing capacity using field density and angle of internal friction as one of the base parameters as presented Figure 16,17 and in any case laboratory test are suggested to obtain the shear strength parameters ( $c$ and $\phi$-values) to validate. However, these findings are applicable for the present study region broadly considering similar geological formation within the southern belt.

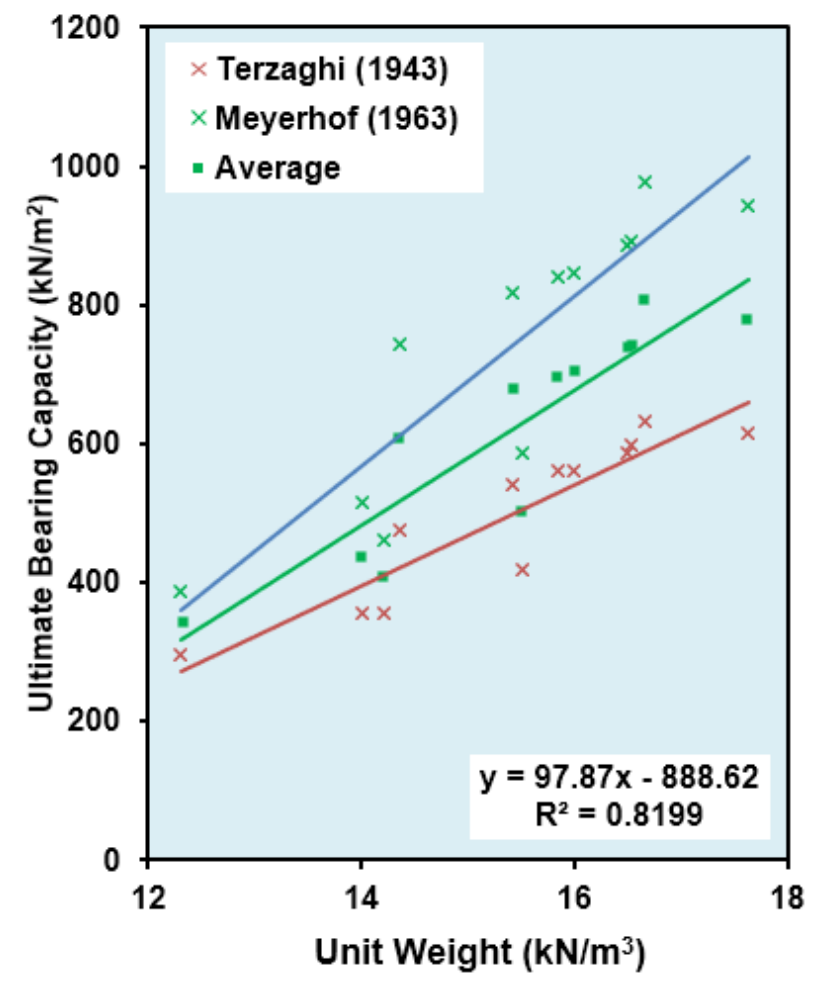

Figure 16. Ultimate bearing capacity and unit weight plot

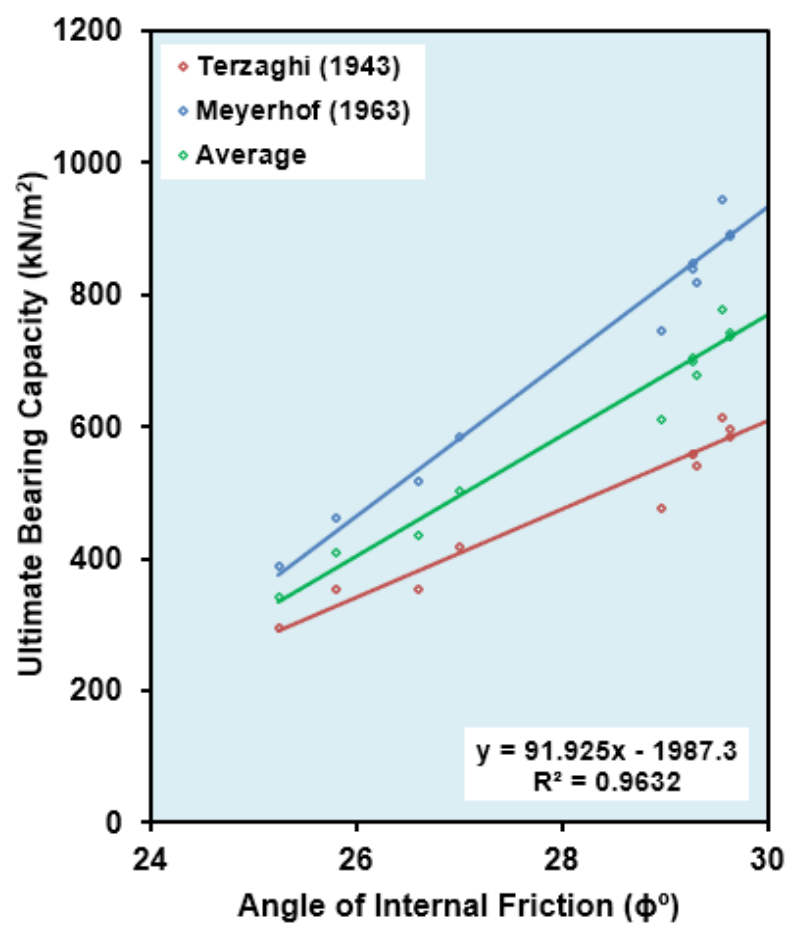

Figure 17. Ultimate bearing capacity and angle of internal friction plot 


\section{Conclusions}

1. Geotechnical investigation through open pit indicates coarse grained soils containing larger portion of sand between $45-65 \%$ followed by gravel of $22-37 \%$ and less than $10 \%$ silt and clay content in the study region. The soil is classified as poorly graded sand of non-plastic (SN-NP) [25].

2. Field density show direct relation to ultimate bearing capacity with correlation coefficient equal to 0.7530 as it represents the physical characteristics of the soil at the site with the actual moisture content. It is recommended to conduct the field density test at the same depth of exploration. Similarly, correlation coefficient between ultimate bearing capacity and angle of internal friction is 0.9632 , suggesting conceivable approximation of ultimate bearing capacity using field density and angle of internal friction in the study region.

3. PLT results have shown ultimate bearing capacity ranging between 275 to $785 \mathrm{kN} / \mathrm{m}^{2}$ approximately in eight study locations for embedment depth of $1.5 \mathrm{~m}$. Increase in the size of the footing will result is higher ultimate bearing capacity similar to results of SPT.

4. Meyerhof empirical relation produced more conservative ultimate bearing capacity compared to results of Terzaghi using SPT $N$-values which is in accordance to numerous past studies. The ultimate bearing capacity is minimum as $294 \mathrm{kN} / \mathrm{m}^{2}$ for lower width of footing and maximum up to $1300 \mathrm{kN} / \mathrm{m}^{3}$ approximately for higher width of footing with Terzaghi's correlation. On the other hand, Meyerhof's approximation had indicated minimum of $389 \mathrm{kN} / \mathrm{m}^{2}$ at lower width of footing and 1754 $\mathrm{kN} / \mathrm{m}^{2}$ for higher footing width. Gedu area suffer much lower ultimate bearing capacity compared to other sites in both Terzaghi and Meyerhof's methods.

5. All the parametric analysis shows linear correlations between each of the parameters. Bearing capacity factors indicate an exponential function of angle of internal friction $(\phi)$ [13]. All the investigated sites contain suitable soils for shallow foundations for any infrastructure development projects.

\section{Acknowledgements}

The authors are thankful to College of Science and Technology for laboratory facilities and Department of Geology and Mines (DGM) for providing technical reports. The field data is a record of consultancy services carried out by the authors.

\section{REFERENCES}

[1] Chettri N., Gautam D., Rupakhety R., "Seismic Vulnerability of Vernacular Residential Buildings in Bhutan,” J. Earthq. Eng., vol. 00, no. 00, pp. 1-16, 2021, doi: 10.1080/13632469.2020.1868362.

[2] Tempa K., Chettri N., Gurung L., Gautam D.,"Shear wave velocity profiling and ground response analysis in Phuentsholing, Bhutan," vol. 6, no. 2, pp. 1-16, 2021, doi: 10.1007/s41062-020-00420-w.

[3] Tempa K., et al., "Parametric study of local site response for bedrock ground motion to earthquake in Phuentsholing, Bhutan," Sustain., vol. 12, no. 13, 2020. doi: 10.3390/su12135273.

[4] Tempa K., Chettri N., "Geotechnical Site Investigation for Infrastructure Development Project at Jigmeling Industrial Estate in Sarpang, Bhutan," Int. J. Emerg. Technol., vol. 11, no. 5, pp. 143-149, 2020. https://www.researchtrend.net/ije t/current_issue_ijet.php?taxonomy-id=82\#

[5] Fourie A., Vawda A., "The importance of a thorough geotechnical site investigation at the planning stage of urban development," Urban Forum, vol. 3, no. 1, pp. 57-72, 1992. doi: 10.1007/BF03036539.

[6] Tempa K., Chettri N., Sarkar R., Saha S., Gurung L., Dendup T., Nirola B. S., "Geotechnical parameter assessment of sediment deposit: A case study in Pasakha, Bhutan," pp. 0-21, 2021, doi: $10.1080 / 23311916.2020 .1869366$.

[7] Ali T. S., Fakhraldin M. K., "Soil parameters analysis of Al-Najaf City in Iraq: case study," J Geotech Eng, vol. 3, no. 1, pp. 1987-2394, 2016. http://engineeringjournals.stmjou rnals.in/index.php/JoGE/article/view/3749.

[8] Park M. J., Yeom T. J., Ju J. S., Park K. G., "Earthquake response and pushover analysis of piloti buildings supported by src columns," Civil Engineering and Architecture, vol. 8, no. 2, pp. 166-190, 2020. doi: $10.13189 /$ cea.2020.080214.

[9] Akpila S. B., "Bearing Capacity and Settlement Response of Raft Foundation on Sand Using Standard Penetration Test Method," Can. J. Pure Appl. Sci., vol. 8, no. 1, pp. 27692774, 2014. http://www.cjpas.net/wp-content/uploads/pdfs/ 8/1/Paper\%20(15).pdf.

[10] Tempa K., Chettri N., Yangzom D., Chettri I. B., Jamtsho Y., "Subsurface Exploration for Road Sinking at Sorchen and Counter Measures," 23-24th December, 2016. http://iepkarachi.org.pk/8th_International.html?fbclid=IwA R29Y0DnCWvF4X99-7QBX1QpQgLVlmpqnAcjAWt_d9 N431jAAHYEf-whuFM.

[11] IS:1888 (Reaffirmed 2002), "Method of Load Test on Soils," Bureau of Indian Standards, New Delhi, India, 1982.

[12] IS:2131, "Method For Standard Penetration Test For Soils," New Delhi: Bureau of Indian Standards, New Delhi, India, 1981.

[13] Esmali A., Gholami M., "Analytical model for the ultimate bearing capacity of foundations from cone resistance," Sci. Iran., vol. 13, no. 3, pp. 223-233, 2006. $\mathrm{http}: / /$ scientiairanica.sharif.edu/article_2580_141a0af585e6 7ec034d7579352b3a4d5.pdf. 
[14] Terzaghi K., "Theoritical Soil Mechanics," American Society of Civil Engineers, USA, 1943.

[15] Meyerhof G. G., "The ultimate bearing capacity of foundations," in Geotechnique, vol. 2, no. 4, pp. 301-332, 1951.

[16] Meyerhof G. G., "Penetration Tests and Bearing Capacity of Cohesionless Soils," J. Soil Mech. abd Found. Div., vol. 82, no. 1, pp. 1-19, 1956. https://cedb.asce.org/CEDBsearch/re cord.jsp?dockey $=0010801$.

[17] Hansen J. B., "A General Formula for Bearing Capacity," The Danish Geotechnical Institute, 1961.

[18] Murthy V. N. S., "Advanced Foundation Engineering Geotechnical Engineering Series," CSB Publishers \& Distributers, New Delhi,India, 2007.

[19] Bowles J. E., "Foundation Analysis and Design," The McGraw-Hill Companies, Inc., Sigapore, 1996.

[20] Zumrawi M. M. E., Elnour H., "Predicting bearing strength characteristics from soil index properties," Int. J. Civ. Eng. Technol., vol. 7, no. 2, pp. 266-277, 2016. http://www.iaeme.com/MasterAdmin/Journal uploads/IJCI ET/VOLUME_7_ISSUE_2/IJCIET_07_02_023.pdf.

[21] Akpila S. B., "Comparison of standard penetration test methods on bearing capacity of shallow foundations on sand," Sci. J. Pure Appl. Sci., vol. 2, no. 2, pp. 72-78, 2013. doi: 10.14196/sjpas.v2i2.570.

[22] Meyer Z., Cichocki P., "Analysis of combined pile raft foundations based on a static load test," Civil Engineering and Architecture, vol. 8, no. 2, pp. 101-112, 2020. doi:10.13189/cea.2020.080208.

[23] Mittal S., Shukla J. P., "Soil Testing for Engineers," Khanna Publishers, New Delhi, India, 2008.

[24] IS:1904 (Reaffirmed 2006), "Code of Practice for Design and Construction of Foundation in Soils: General Requirements," Bureau of Indian Standards, New Delhi, India, 1986.

[25] IS:1498, "Classification and identification of soils for general engineering purposes," Bureau of Indian Standards, New Delhi, India, 1970.

[26] Kuenza K., Dorji Y., Wangda D., "Landslides in Bhutan," Ctry. Report, Dep. Geol. Mines, R. Gov. Bhutan, Thimphu, pp. 73-80, 1994. https://www.preventionweb.net/files/1479 3 SAARClandslide.pdf.

[27] Dini B., Manconi A., Loew S., "Investigation of slope instabilities in NW Bhutan as derived from systematic DInSAR analyses," Eng. Geol., vol. 259, no. 105111, pp. 1-19, 2019. doi: https://doi.org/10.1016/j.enggeo.2019.04.0 08

[28] Department of Geology and Mines, "Technical Report of DGM : proposed landslide mitigations in P / Ling Thromde," pp. 1-60, 2009.
[29] Department of Geology and Mines, "Integrated Geo-Hazard Risk Assessment of Critical Landslide at Arong / Lamsorong, Samdrupjongkhar-Trashigang Highway, under Samdrupjongkhar Dzongkhag," Thimphu, Bhutan, 2016.

[30] Department of Geology and Mines, "Hazard assessment of extended Phuentsholing Township and Ahaley-Toribari Areas under Chukha Dzongkhag," Ministry of Economic Affairs, Thimphu, Bhutan, 2010.

[31] IS:2720 (Part 4), "Methods of Test for Soils, Part 4: Grain Size Analysis," Bureau of Indian Standards, New Delhi, India, 1985.

[32] IS:1893, "Criteria for Earthquake Resistant Design of Structures: General Provisions and Buildings Part-1," Bureau of Indian Standards. New Delhi, vol. Part 1, pp. 1-39, 2002.

[33] Gopal R., Rao A. S. R., "Basic and Applied Soil Mechanics," New Age International Publishers, New Delhi, India, 2000.

[34] Acharya M., Acharya I. P., "Reliability Analysis of Bearing Capacity of Shallow Foundation on c- $\phi$ Soil," J. Adv. Coll. Eng. Manag., vol. 5, pp. 71-78, 2019. doi: 10.3126/jacem.v5i0.26690.

[35] Cubrinovski M., Ishihara K., "Empirical Correlation between SPT N-value and Relative Density for Sandy Soils," Soils Found. Japanese Geotech. Soc., vol. 39, no. 5, pp. 6171, 1999. doi: https://doi.org/10.3208/sandf.39.5_61.

[36] IS:2720 (Part 29), Indian Standard, Method of Test for Soils: Determination of Dry Density of Soils In-place by the Core-Cutter Method. Bureau of Indian Standards, New Delhi, India., 1975.

[37] Kalinski M. E., "Soil Mechanics Lab Manual,” John Wiley \& Sons, Inc., 2011.

[38] Peck R. B., Hanson W. E., Thornburn T. H., "Foundation Engineering," 2nd ed., New York: John Wiley \& Sons, 1974.

[39] Budhu M., "Soil Mechanics Fundamentals," Wiley Blackwell, UK, 2015.

[40] Ohsaki Y., "Geotechnical Properties of Tokyo Subsoils," Soils Found., vol. 2, no. 2, pp. 17-34, 1962, doi: https://doi.org/10.3208/sandf1960.2.2_17.

[41] Kumar R., Bhargava K., Choudhury D., "Estimation of Engineering Properties of Soils from Field SPT Using Random Number Generation," Ina. Lett., vol. 1, no. 3-4, pp. 77-84, 2016. doi: 10.1007/s41403-016-0012-6.

[42] Aysen A., "Problem Solving in Soil Mechanics," A.A. Balkema Publishers, Tokyo, 2003.

[43] Venkatramaiah C., "Geotechnical Engineering," New Age International Publishers, New Delhi, India, 2016.

[44] Das B. M., "Principles of Geotechnical Engineering," Cengage Learning, USA, 2010. 